\title{
Family-Centered Education and Self-care Behaviors of Patients With Chronic Heart Failure
}

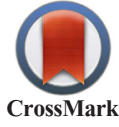

\author{
Alice Khachian ${ }^{1}$, Mahnaz Seyedoshohadaee ${ }^{1}$, Hamid Haqhani² $^{2}$ Freshteh Aghamohammadi ${ }^{*}$ \\ 1. Department of Medical Surgical Nursing, School of Nursing and Midwifery, Iran University of Medical Sciences, Tehran, Iran. \\ 2. Department of Statistics, School of Public Health, Iran University of Medical Sciences, Tehran, Iran.
}

ditation: Khachian, A., Seyedoshohadaee, M., Haqhani, H. \& Aghamohammadi, F. 2016. Family-Centered Education and Self-care Behaviors of Patients With Chronic Heart Failure. Journal of Client-Centered Nursing Care, 2(3), pp. 177-184. https://doi.org/10.32598/jccnc.2.3.177

oit: : https://doi.org/10.32598/jecnc.2.3.177

Article info:

Received: 03 Feb. 2016

Accepted: 01 Jun. 2016
Keywords:

Chronic heart failure, Self-care, Education, Family-centered approach

\begin{abstract}
A B S T RA C T
Background: As for high prevalence and incidence of heart failure, it can impose huge health, economic, and social burden on society. Education and self-care are important aspects of management in patients with heart failure, which can control the disease complications. This study aimed to investigate the effect of family-centered education approach on self-care behaviors of the patients with heart failure.

Methods: This research is a randomized clinical trial. The study has been conducted on 72 patients with heart failure hospitalized in Shahid Rajai cardiovascular, medical, and research center, Tehran, Iran, in 2015. Patients were randomly assigned into the intervention (familycentered) and control groups. The self-care behaviors were measured before and two months after intervention using questionnaires of the self-care behaviors. Data analysis was done using paired $t$ test and independent $t$ test by SPSS.
\end{abstract}

Results: Before intervention, mean (SD) values of self-care scores were 23.88 (4.71) and 21.50 (3.30) in the control and family-centered groups, respectively, with no statistically significant difference between two groups $(\mathrm{P}=0.064)$. Two months after the intervention, mean (SD) values of self-care scores in control and intervention groups were 22.94 (4.71) and 42.31 (4.60), respectively. Statistical analysis showed that self-care behaviors in the family-centered group had a significant increase compared to the control group $(\mathrm{P}<0.001)$.

Conclusion: Education with family-centered approach has a positive impact on the self-care behavior of patients with heart failure. With regard to our culture and the importance of family, it is suggested that this approach be used in addition to other training methods to improve self-care behaviors in patients with chronic diseases such as heart failure.

\section{* Corresponding Author:}

Freshteh Aghamohammadi, MSc.

Address: Department of Medical Surgical Nursing, School of Nursing and Midwifery, Iran University of Medical Sciences, Tehran, Iran. Tel: +98 (919) 7062974

E-mail: aghamohamadif1@gmail.com 


\section{Background}

$\int$

$\mathrm{n}$ the 20th century, cardiovascular diseases accounted for less than $10 \%$ of all deaths around the world. But by the 21st century, cardiovascular diseases are responsible for almost half of all deaths in developed countries and $25 \%$ of deaths in developing countries. It is anticipated that by 2020 , cardiovascular diseases will result in the death of 25 million people (Azizi et al. 2012). One of the common cardiovascular diseases is chronic heart failure (CHF) where cardiac output cannot provide needed oxygen to the body tissues (Seraji et al. 2013). According to the World Health Organization, $\mathrm{CHF}$ is one of the most common heart diseases, affected $2 \%$ to $4 \%$ of the world's population. Its prevalence increases annually and associates with social and psychological burden and high rate of hospitalization (Albno et al. 2014). Moreover, CHF is the first cause of death in Iran which has the economic and social consequences as well (Seraji et al. 2013). This illness has poor prognosis and high mortality rate so that $40 \%$ of people hospitalized with CHF would die or rehospitalized within one year (Löfvenmark et al. 2011). This unfortunate outcome could be due to patients' poor self-care (Piamjariyakul et al. 2012).

Self-care is a series of activities that purposefully engages person's life in order to promote his or her physical, mental, and emotional health; preserve life; and prevent disease. Patient's participation in self-care is necessary to achieve a positive outcome in health activities (Buck et al. 2014). Learning self-care behaviors can help patients maintain good health and well-being, increase their compatibility with disease and capabilities for self-care. Self-care is also an important component of managing chronic diseases (Khosh Tarash et al. 2013). Follow-up and implementation of self-care behaviors in patients with chronic diseases is of great importance. Patients who are aware of self-care skills can promote their health functional abilities and reduce their complications.

Because of disease complications and treatment processes, patients with CHF experience many changes and challenges in their care plan. These people require appropriate self-care to cope with their condition. In recent years, more emphasis has been upon support and education of patients with CHF with regard to their care (Albno et al. 2014). The offered training can be provided for two target groups of patients and their families. Moreover, training in both groups can play a positive role in reducing stress (of family members and the patient), ris- ing awareness of the disease and its control, and increasing family performance (Löfvenmark 2011).

The nature of heart failure as a chronic disease engages family members, too. Family members can contribute in the responsibility for patient care; therefore, training family members can be among logical and effective components in caring patients with CHF (Dunbar et al. 2013). Family members usually are informally involved in providing care and services for their patients and are considered a resource for patient care (Strömberg 2013). Strömberg reported that cooperation among patient, his/ her family, and health care team has outstanding positive effect on the goals of these three groups and can improve patient care plans, reduce the hospitalization rate, and increase patients' quality of life (Strömberg 2013). Familycentered care is a way to expand health care which shows importance of family in patient care program (Festini 2014). Regarding the role of nurses in health improvement and self-care training and also considering the time nurses spend with family members of patients, they can take a positive step in family-centered education in order to empower patients and improve patients care.

Regarding that most studies are now based on education to patients and less attention has been paid to the role of the patient's family as a valuable source in achieving therapeutic goals, it seems that family-centered education along with patient education could be effective in recognition of the patient's needs.

\section{Materials and Methods}

This research is a clinical trial with a control group. Prior to conducting the study, it was registered by Ethics Committee of Iran University of Medical Sciences (No. 632/105/D/94). Research setting was Shahid Rajai Educational and Therapeutic Research Center of Cardiovascular Diseases. The study population were inpatients with $\mathrm{CHF}$ in the center and their active family members. The study sample were recruited from internal and post $\mathrm{CCU}$ wards (women and men).

Inclusion criteria for the patients were as follows: being 18 years or older, confirmation of the heart failure diagnosis by a physician (in their medical records), having heart failure with $35 \%$ ejection fraction or less, not being in acute condition, no sensory-perceptual problem and visual, hearing, and communication disturbances, willingness to participate in the study, having a caregiver (an active family member) who met the inclusion criteria, and lack of participation in the similar study. Inclusion criteria for active family member were as follows: being 
illiterate, willingness to participate in the study, and at least three months responsibility for patient care. Exclusion criteria were as follows: absence from the training sessions for more than one session for the intervention group, unwillingness to participate in the study for both groups, patient's death, worsening the patient's condition, transferring to another department, prolonged hospitalization (more than 1 month), and getting high scores on self-care questionnaire before the intervention.

Data collection instruments comprised demographic form of the patients and their active family members. Demographic form of the patients included questions about age, gender, education level, marital status, history of underlying disease, body mass index, ejection fraction of heart, duration of heart failure, underlying disease, disease severity, cause of heart failure, family history of the disease, number of children, income status, medications and the frequency of drug use. Part of this form was completed by the patient and part of it by the researcher according to their medical records.

Demographic form of the active family members included questions about age, gender, education level, marital status, and duration of patient care and was completed by the active member of family. To investigate self-care behaviors, a questionnaire measuring self-care behaviors was administered to patients with $\mathrm{CHF}$. The questionnaire was designed by Shojaei et al. in 2008 and its content validity was confirmed by a panel of experts and the Cronbach $\alpha$ coefficient of the questionnaire was calculated as 0.8 . It included 15 questions about selfcare which were scored based on Likert-type scale. In this study, the reliability and validity of these two instruments was revised by expert opinions.

With regard to face and content validity of the questionnaire and according to the opinion of the professors in School of Nursing and Midwifery of Iran University of Medical Sciences, one question about exercise with the title of "I regularly do exercise at least three times a week" added to this questionnaire to be investigated by necessary measures before and after the intervention. Eventually, total score of this questionnaire ranged between 0 and 64; 0-21 scores means poor care, 22-43 scores means average care, and 44-64 scores shows good care. The Cronbach $\alpha$ coefficient of the questionnaire was 0.75 .

The sample size was determined with $95 \%$ of confidence, power of $80 \%$, and assuming that family-based education approaches affects self-care behavior score with a significant difference of $d=4$ (compared with the control group). The obtained number in each group was
32 and considering 25\% samples drop, 40 patients in each group were recruited.

Before sampling, all patients who met the inclusion criteria and would like to participate in the study, completed informed consent forms. The patients were randomly put in the family-centered group and control group. Demographic questionnaire and a questionnaire measuring self-care behaviors of patients with CHF were completed by subjects before the intervention. The familycentered group involving patients and family members were asked to participate in three sessions about topics related to self-care held by the study researcher at the hospital. Each session was scheduled for 45 minutes and according to the needs of the patients and family members, continued up to 60 minutes.

This training was conducted in lecture form and in a group (if possible) with a maximum number of 10 people along with questions, answers, and images. Educational content included the introduction of disease, $\mathrm{CHF}$, risk factors, symptoms, diet, proper exercise, medication, proper care principles and disease management. Control group just received the routine common care training in the hospital. Phone numbers of both groups were taken for follow-up and communication with the researcher. Groups received 2 phone calls of approximately 5 minutes after discharge from the hospital. Its content was based on the needs of patients or educational content provided to them. Also, number of the researcher was given to both groups to contact with the researcher in case of having questions or problems.

Two months after the educational program, the researcher after coordination with both groups and when they referred to the hospital to control the treatment process, asked them to complete the questionnaire of measuring self-care behaviors. The data, then, were entered into SPSS version 21 and were analyzed using descriptive (mean, standard deviation, frequency) and inferential statistics (paired t-test and independent t-test).

\section{Results}

The study results showed that the mean (SD) participants' ages in the family-centered groups were 49.50 (9.74) years and in the control group 55.53(13.67) years (Table 1). In terms of gender, control and family-centered groups were homogenous. In both groups, most participants were married and housewives. However in terms of education level, two groups were heterogeneous. According to the statistical tests determining the effect of education on self-care 
Table 1. Demographic characteristics of study samples.

\begin{tabular}{|c|c|c|c|c|c|c|}
\hline \multirow{2}{*}{ Variable } & & \multicolumn{2}{|c|}{ Control $(n=36)$} & \multicolumn{2}{|c|}{ Family-Centered $(n=36)$} & \multirow{2}{*}{ Sig. } \\
\hline & & Mean or No. & SD or $\%$ & Mean or No. & SD or \% & \\
\hline Age (y) & & 55.53 & 13.67 & 49.50 & 9.74 & ${ }^{*} P=0.0055$ \\
\hline \multirow{2}{*}{ Gender } & Female & 18 & 50 & 18 & 50 & \multirow{2}{*}{$* * P=0.99$} \\
\hline & Male & 18 & 50 & 18 & 50 & \\
\hline \multirow{5}{*}{ Marital status } & Single & 1 & 2.8 & 1 & 2.8 & \multirow{5}{*}{$P=0.99$} \\
\hline & Married & 33 & 91.7 & 34 & 94.4 & \\
\hline & & & & & & \\
\hline & Divorced & 1 & 2.8 & 0 & 0 & \\
\hline & Widow & 1 & 2.8 & 1 & 2.8 & \\
\hline \multirow{6}{*}{ Job } & Unemployed & 2 & 5.6 & 1 & 2.8 & \multirow{6}{*}{$* * * P=0.075$} \\
\hline & Housewife & 18 & 50 & 15 & 41.7 & \\
\hline & Employee & 2 & 5.6 & 3 & 8.3 & \\
\hline & Freelance & 3 & 8.3 & 11 & 30.6 & \\
\hline & Retired & 7 & 19.4 & 6 & 16.7 & \\
\hline & Other & 4 & 11.1 & 0 & 0 & \\
\hline \multirow{4}{*}{ Education level } & Elementary & 21 & 58.3 & 8 & 22.2 & \multirow{4}{*}{$* * P=0.015$} \\
\hline & High school & 7 & 19.4 & 17 & 47.2 & \\
\hline & Diploma & 6 & 16.7 & 8 & 22.2 & \\
\hline & Undergraduate & 2 & 5.6 & 3 & 8.3 & \\
\hline \multirow{3}{*}{ Income sufficiency } & Sufficient & 5 & 13.9 & 3 & 8.3 & \multirow{3}{*}{$* * * P=0.596$} \\
\hline & Almost sufficient & 15 & 41.7 & 19 & 52.8 & \\
\hline & Is not sufficient & 16 & 44.4 & 14 & 38.9 & \\
\hline \multirow{3}{*}{ Smoking } & Yes & 8 & 22.2 & 8 & 22.2 & \multirow{3}{*}{$* * P=0.99$} \\
\hline & No & 22 & 61.1 & 23 & 63.9 & \\
\hline & Quitted & 6 & 16.7 & 5 & 13.9 & \\
\hline \multirow{2}{*}{ Exercise program } & Yes & 15 & 41.7 & 3 & 8.3 & \multirow{2}{*}{$* * \mathrm{P}=0.002$} \\
\hline & No & 21 & 85.3 & 33 & 91.7 & \\
\hline \multirow{2}{*}{$\begin{array}{l}\text { History of heart failure in } \\
\text { family }\end{array}$} & Yes & 15 & 41.7 & 21 & 58.3 & \multirow{2}{*}{$* * P=0.23$} \\
\hline & No & 21 & 58.3 & 15 & 41.7 & \\
\hline \multirow{3}{*}{ Cause of heart failure } & Ischemic & 13 & 1.36 & 8 & 22.2 & \multirow{3}{*}{$* * P=0.3$} \\
\hline & & & & & & \\
\hline & Non-ischemic & 23 & 9.63 & 28 & 77.8 & \\
\hline Ejection fraction of heart & Mean (SD) & 26.39 & 6.29 & 26.94 & 5.64 & $* P=0.875$ \\
\hline $\mathrm{BMI}\left(\mathrm{kg} / \mathrm{m}^{2}\right)$ & Mean (SD) & 25.26 & 5.11 & 25.53 & 5.49 & $* P=0.754$ \\
\hline
\end{tabular}


Table 2. Self-care score results in two study groups before and after the intervention.

\begin{tabular}{|c|c|c|c|c|c|c|c|c|c|}
\hline \multirow{3}{*}{ Group } & \multicolumn{4}{|c|}{ Control } & \multicolumn{4}{|c|}{ Family-Centered } & \multirow{3}{*}{$\begin{array}{c}\text { Inde- } \\
\text { pendent } \\
\text { Sample } \\
\text { T-Test }\end{array}$} \\
\hline & \multicolumn{2}{|c|}{$\begin{array}{l}\text { Before Interven- } \\
\text { tion }\end{array}$} & \multicolumn{2}{|c|}{$\begin{array}{l}\text { Two months After } \\
\text { Intervention }\end{array}$} & \multicolumn{2}{|c|}{$\begin{array}{l}\text { Before Interven- } \\
\text { tion }\end{array}$} & \multicolumn{2}{|c|}{$\begin{array}{c}\text { Two Months } \\
\text { After Intervention }\end{array}$} & \\
\hline & $\%$ & No. & $\%$ & No. & $\%$ & No. & $\%$ & No. & \\
\hline Weak self-care score $(0-21)$ & 36.1 & 13 & 41.7 & 15 & 44.4 & 16 & 0 & 0 & \\
\hline Average self-care score (22-43) & 63.9 & 23 & 58.3 & 21 & 55.6 & 20 & 58.3 & 21 & \\
\hline Good self-care score (22-43) & 0 & 0 & 0 & 0 & 0 & 0 & 41.7 & 15 & $P<0.001$ \\
\hline Mean \pm SD & \multicolumn{2}{|c|}{$23.88 \pm 4.71$} & \multicolumn{2}{|c|}{$22.94 \pm 4.71$} & \multicolumn{2}{|c|}{$21.50 \pm 3.30$} & \multicolumn{2}{|c|}{$42.31 \pm 4.60$} & \\
\hline Paired sample t-test & \multicolumn{2}{|c|}{$t=2.7$} & \multicolumn{2}{|c|}{$35 \quad P=0.01$} & \multicolumn{2}{|c|}{$t=-27.07$} & $347 \quad P$ & 001 & \\
\hline
\end{tabular}

Client-Centered Nursing Сare

behaviors, this variable had no interfering effect in the study and is not an extraneous variable $(\mathrm{P}=0.168)$.

In terms of income level, the most frequency statement in the control group was "which is not enough" and in family-centered group, "is partially sufficient." The results indicated that smoking habit was similar in both groups and most participants in the control group and familycentered were non-smokers. In terms of regular exercise program, significant difference was observed between the two groups. According to statistical tests to determine the effect of the interaction of these variables on self-care behaviors, this variable had no interfering effect in this study and it was not an extraneous variable $(\mathrm{P}=0.168)$.

Investigations also revealed that the majority of patients in both groups had a family history of heart disease and non-ischemic reasons were the most frequent cause of heart failure in patients. Also the ejection fraction of the heart in both groups were mostly around $24 \%$ to $30 \%$. Both groups were also homogenous in terms of body mass index. In family-centered group, it was mostly around 25 to $30 \mathrm{~kg} / \mathrm{m}^{2}$ in the control group around 18.5 to $25 \mathrm{~kg} / \mathrm{m}^{2}$.

Before intervention, the mean (SD) self-care scores in family-centered and control groups were 23.88(4.71) and 21.50(3.30), respectively. No statistically significant difference observed between self-care scores of two groups $(\mathrm{P}=0.064)$. Two months after the intervention, the mean (SD) self-care scores in control and family-centered groups were 22.94 (4.71) and 42.31 (4.60), respectively. Statistical analysis showed that self-care behaviors in family-centered group had a significant increase compared to the control group $(\mathrm{P}<0.001)$.

Paired sample t-test showed a significant difference between the means of self-care score in the control group before and two months after intervention $(\mathrm{P}=0.01)$ which this change was negative. There was a significant difference between self-care scores of the familycentered group before and two months after intervention ( $\mathrm{P}<0.001)$. Also, a significant difference was observed between the control group and family-centered groups after the intervention $(\mathrm{P}<0.001)$ (Table 2$)$.

\section{Discussion}

The purpose of this study was to investigate the effect of self-care education with the family-centered approach on self-care behavior of patients with CHF. In this study, 72 patients with heart failure and active members of their families attended.

This study showed that before the intervention, in the family-centered group $55.6 \%$ of participants had average score of self-care (score $22-43$ ) and $44.4 \%$ had poor self-care score (0-21). The mean (SD) of self-care behaviors score in this group was 21.50 (3.30) before the intervention. But two months after educational intervention in this group, 21 (58.3\%) participants had average selfcare score and $15(41.7 \%)$ subjects had good self-care score. Statistical analysis revealed that the difference was statistically significant between self-care behaviors in the family-centered group $(\mathrm{P}<0.001)$ before and two months after intervention. Likewise, Srisuk et al. in their study reported that after holding training sessions for 50 patients and an active caring member of their family in the intervention group, family member's knowledge and self-care of patients with CHF increased, compared to the control group who received routine care and education (Srisuk et al. 2014).

Similarly, Shahriyari et al. reported that the self-care behaviors of the family-centered group, which involved patients and their active caring family members, increased significantly after intervention, compared to the 
control group in which only the patients were present ( $\mathrm{P}$ $<0.001)$. In their study, mean (SD) scores of the selfcare behaviors in the family-centered and in the control group were 26.9(4.9) and 27.2(4.3), respectively before the intervention (Shahriari et al. 2013).

These scores were similar to the results of our study in terms of obtaining average self-care score in family-centered and control groups before the intervention. However, the mean (SD) of self-care behaviors after educational intervention for the family-centered group and the control group were 47.2(6.3) and 28.4(3.9), respectively. Therefore their study results were similar to the current study in terms of obtaining good self-care score in family-centered group and average self-care score in the control group.

Bahramnezhad et al. in a quasi-experimental study with the aim of comparing the effect of individual- and familycentered education on controlling blood pressure reported that education in the family-centered group can have a positive impact on patients' blood pressure $(\mathrm{P}=0.0005)$ (Bahramnezhad et al. 2008). Furthermore, Ghavidel et al. reported that family-centered education can improve the quality of life in patients undergoing coronary artery bypass surgery $(\mathrm{P}<0.0001)$ (Ghavidel et al. 2015).

Dunbar et al. reported that self-care behaviors such as reducing sodium intake in diet in groups of "patient and family participation" and "educating patients and families" significantly increased compared to control group (P $=0.018$ ). Also the control group was less likely to follow a low-sodium diet compared to the other groups. The urinary sodium in the group of "patient and family participation" and "educating patients and families" significantly decreased compared to the control group ( $\mathrm{P}=0.016)$. Their study introduced family members as a supportive element in promoting self-care behaviors (Dunbar et al. 2013). To verify these results, studies have been conducted on other chronic diseases such as diabetes.

Sadeghi et al. reported that there was a statistically significant difference between family-centered educational intervention compared to patient-centered and the control group with regard to knowledge $(\mathrm{P}<0.001)$ and indicators of metabolic control (HBA1C) $(\mathrm{P}>0.05)$ (Razi et al. 2013).

In conclusion, family-centered education approach can positively impact self-care behaviors of patients with CHF. Although education has positive effects, such educational approaches as family-centered can increase several folds the impact of education on the patients. With regard to the significance of family in disease control and complications of chronic diseases on one hand, and the importance of family in Iranian culture on the other hand, this educational approach can be used to improve self-care process in patients with chronic diseases such as heart failure.

\section{Acknowledgments}

This article is extracted from the MSc. thesis of the corresponding author, Department of Medical Surgical, School of Nursing and Midwifery, Iran University of Medical Sciences. The authors would like to express their special gratitude to members of the Department of Surgery and the Graduate School of Nursing and Midwifery, Iran University of Medical Sciences. Moreover, the authors also would like to make special reference to all staff at Shahid Rajaee Heart Center without whose cooperation; this process could have not fulfilled.

\section{Conflict of Interest}

The authors declared no conflict of interests.

\section{Reference:}

Bahrami Nejad, N., Hanifi, N., Moosavi Nasab, N. 2008. '[Comparing the effect of two family- and individual-based interventions on blood pressure and lifestyle (Persian)]'. Journal of Qazvin University of Medical Sciences, 12(1), pp. 62-79.

Razi Shadan, P., Sadeghi, M., Nikbakht Nasrabadi, A. R., Ebrahimi, H., Kazemnejad, A. 2014. '[The effect of familycentered empowerment model on knowledge and metabolic control of patients with type 2 diabetes (Persian)]'. Journal of Knowledge \& Health, 9(1), pp. 48-54. doi: 10.1234/knh.v9i1.348

Khoshtarash, M., Momeni, M., Ghanbari, A., Salehzadeh, A. H., Rahmatpour, P. 2013. '[Self-care behaviors and related factors in patients with heart failure reffering to medical \& educational center of heart in Rasht (Persian)]'. Holistic Nursing and Midwifery Journal, 23(1), 22-9.

Azizi, F., Agha Abbaslou, M., Janghorbani, M., Hatami, H. 2010 Epidemiology and control of common diseases in Iran (Persian)]. Khosravi Publication, Tehran.

Ataee, E., Haghjoo, M., Dalvandi, A., Bakhshandeh, H. 2013. [Effect of self-care education on quality of life among patients with permanent pacemaker (Persian)]. Cardiovascular Nursing Journal, 1(4), pp. 40-7.

Ghavidel, A., Farokhnezhad-Afshar, P., Bakhshandeh, H., Ghorbanpour, F. 2015. '[Effect of family-centered education on the quality of life patients after coronary artery bypass graft surgery (Persian)]'. Cardiovascular Nursing Journal, 4(2), pp. 6-13. 
Khorami Markan, A., Saheli, S., Sakhaei, S., Khalkhali, H. R. 2015. '[Assessment the effect of family centered care educational program on home care knowledge among care givers of patients with chronic renal failure under hemodialysis (Persian)]'. Journal of Nursing and Midwifery Urmia University of Medical Sciences, 13(5), pp. 386-94.

Albano, M. G., Jourdain, P., De Andrade, V., Domenke, A., Desnos, M., \& D'ivernois, J. F. 2014. 'The rapeutic patient education in heart failure: Do studies provide sufficient information about the educational programme?' Archives of Cardiovascular Diseases, 107(5), pp. 328-39. doi: 10.1016/j. acvd.2013.12.002

Buck, H. G., Harkness, K., Wion, R., Carroll, S. L., Cosman, T., Kaasalainen, S., et al. 2014. Caregivers' contributions to heart failure self-care: A systematic review. European Journal of Cardiovascular Nursing, 14(1), pp. 79-89. doi $10.1177 / 1474515113518434$

Dunbar, S. B., Clark, P. C., Reilly, C. M., Gary, R. A., Smith, A., Mccarty, F., et al. 2013. A trial of family partnership and education interventions in heart failure. Journal of Cardiac Failure, 19(12), pp. 829-41. doi: 10.1016/j.cardfail.2013.10.007

Festini, F. 2014. 'Family-centered care'. Italian Journal of Pediatrics, 40(1), pp. 11-14. doi: 10.1186/1824-7288-40-s1-a33

Löfvenmark, C. 2011. Living with heart failure: Effects of an educational programme on patients and family members (PhD thesis). Karolinska Institutet.

Löfvenmark, C., Karlsson, M. R., Edner, M., Billing, E., \& Mattiasson, A. C. 2011. A group-based multi-professional education programme for family members of patients with chronic heart failure: Effects on knowledge and patients health care utilization. Patient Education and Counseling, 85(2), pp. 162-168. doi: 10.1016/j.pec.2010.09.026

Piamjariyakul, U., Smith, C. E., Werkowitch, M. \& Elyachar, A. 2012. Part I: Heart failure home management: Patients, multidisciplinary health care professionals and family caregivers perspectives. Applied Nursing Research, 25(4), pp. 239-245. doi: 10.1016/j.apnr.2011.05.001

Seraii, M., Tabatabaie, P., Rakhshani, F., Shahrakipour, M. 2013. [The Effect of educating self-care behaviors to patients with heart failure in hospitals of Zahedan (Persian)]. Health Scope, 2(2), pp. 104-9. doi: 10.17795/jhealthscope-11414

Shahriari M, Ahmadi M, Babaee S, Mehrabi T, Sadeghi M. 2013. Effects of a family support program on self-care behaviors in patients with congestive heart failure. Iranian Journal of Nursing and Midwifery Research, 18(2), pp. 152-7. PMCID: PMC3748572

Srisuk, N., Cameron, J., Ski, C. F., \& Thompson, D. R. 2014. Trial of a family-based education program for heart failure patients in rural Thailand. BMC Cardiovascular Disorders, 14(1), pp. 17380. doi: 10.1186/1471-2261-14-173

Strömberg, A. 2013. The situation of caregivers in heart failure and their role in improving patient outcomes. Current Heart Failure Reports, 10(3), 270-5. doi: 10.1007/s11897-013-0146-8 
